\title{
Review of $\boldsymbol{A}$ Handbook of Food Crime: Immoral and Illegal Practices in the Food Industry and What to Do About Them, 2018, Allison Gray and Ronald Hinch (Editors)
}

\author{
Policy Press, 2018, 384 pages \\ ISBN: 978-1-44733-601-3 \\ Review by Emmanuel K. Bunei \\ Ph.D. candidate, Faculty of Science, Business, Agriculture and Law \\ University of New England, Australia \\ ebunei@myune.edu.au
}

Everything about food (type, quantity, labeling, consumption, production, marketing, safety, malnutrition, criminality) bristles with public, media and ethical concerns (Manning, 2017). Gray and Hinch's edited Handbook of Food Crime: Immoral and Illegal Practices in the Food Industry and What to Do About Them facilitates an important cross-disciplinary conversation and discussion on one of these concerns (that is crime and criminalities) about food. The book is an excellent introduction to the field of food crime research and policing. It is a first kind of book to wholly focus on food crime, and provides detailed examples of illegalities and immoralities in the food industry from the farm to the dinner table.

The book contains 24 interdisciplinary and transdisciplinary chapters authored by 42 international researchers, academics and scholars from a wide range of professional backgrounds and personal experiences from disciplines such as sociology, law, criminology, economics, environmental studies, epidemiology, management, nursing alongside consultants and policymakers from these disciplines. These authors utilize their own training, experiences, analytical frameworks and practices to interrogate and facilitate readers in understanding the criminological dimensions of food. All the chapters provide sufficient overview, rich, extensive, engaging, provocative and thoughtful criminological gateways and viewpoints that challenged the mainstream ways of thinking about food. All the chapters have introductory and concluding sections that provide readers with a quick snapshot of its content. Also, all the chapters have the exhaustive references that it enables readers to understand more about the illegal and immoral practices in food industry. The first and last chapter is written by one of the editors, provides a concise description of the subject matter of the book.

The editors have arranged these chapters into eight sections of three related but standalone chapters. Each section focus on eight distinct but related themes which enables readers to easily understand and comprehend criminal aspects in different parts of the food system. Each of the eight sections contains three All the sections are unique but have one common thread: an overwhelming focus on food from a criminological perspective. Preceding the eight sections is the editors' introduction, which sets the stage for the presentation of the other sections and chapters.

The first section, "Thinking about food crime," contains a pair of chapters about definitions, perspectives and social construction of food crimes. In these foundational chapters, authors provide various perspectives of understanding crime and harm in food. 
Gray, in the first chapter, provides a working definition of food crime and strongly advises readers to move the definitions from rational and legalistic definitions of crime and criminality in the food system to a broader perspective of social harm spectrum. Gray concludes her introductory chapter by emphasizing that criminology has a big role in food law and policy making. De Rosa, Trabalzi and Pagnani focus on the social construction of food criminality. Using the evil trinity principles (territoriality, institutions, and entrepreneurship), the authors succeed in demonstrating that context (social, economic, legal, political) have a significant impact how harms and crimes in food are defined, perpetrated and responded.

The second section focuses on crime and criminalities in the food production level of the food chain. This level is the most delicate and vital, as it involves a complex relationship between humans (farmers, consumers, family members, and farm workers), animals (livestock), technologies (chemicals, biotech) and environment (agriculture, water, air, soil and so on). Most of the chapters in this section discuss the connection between production challenges and occurrence of unethical and illegal behaviors in food production activities such as forced labor, slavery and child labor. Additionally, one chapter expounds on the impacts of hazardous substance and farm inputs, especially pesticides on farmers, farm workers, animals and those close to farms.

The third section contains chapters that cover illegal and immoral practices in the sphere of food processing. Issues of concern in this section include consumer protection by food processing organizations; combating food adulteration and food environment (physical, social-cultural, economic and policy factors) and how it impacts human health. Generally, the government plays an important role in ensuring consumer safety. Also, the authors in this section demonstrate how food processing entities and restrictive covenants or regulations can be a source of illegalities and immoralities in the food business, albeit nutritionally.

The fourth section on "corporate food and food safety" focuses on the impact of globalization and the quest for profit maximization on food safety issues. It also delves into the role of the state in the occurrence of food problems. The first chapter in this section discusses the problem of food fraud (specifically horsemeat scandal), a problem that is increasingly become a global problem. The second chapter offers some insightful sights on how the state can be caught in food safety scandals by their inability to act when required. The last chapter in this section by Asomah and Cheng concentrates on demonstrating how the quest for profit, greed, industrialization and globalization treadmills are shaping criminality in the food chain.

Illegal and immoral practices in food trading and transportation are considered in detail in the fifth section 'food trade and movement'. The section gives a detailed analysis of crimes and harms in food transportation, food fraud and the need to have transboundary regulations, and lastly, equity and fairness in engagement with key actors in the food business.

Section six delves into illegalities and immoralities in food science and technology. This includes politics, genetic engineering, and agriculture; safety of food processed and produced through technology and regulations, carnism (i.e., the idea that eating meat is "natural" for humans) and use of animal source food. Section seven on "green food" 
concentrates on demonstrating the relationship between food, food systems and environmental harms. The first chapter, by White and Yeates, discuss the relationship between food production, climate change, and criminality. The second chapter in this section by Long and Lynch's chapter on food waste demonstrates how disposal of excess food has become an avenue for oppression, manipulation, and abuse. The last chapter focus on the problems and crimes associated with the commodification of food. Using two national school feeding programs in Canada and Brazil, the authors of this chapter succeeds in demonstrating how food policy is designed can either prevent or enhance social, political, environmental or public harms. The final section delves into crime and criminalities in food consumption, an important activity in the food chain. Chapters in this section focus on human behaviors toward the tail end of the food chain. This includes the impact of supermarkets on food chain illegalities, food waste, and food advertising; reaction and response of food companies and consumers to food scares; food social movements and food policing. The book ends with some reflections by Gray on "responding to food crime and the threat of the "food police". Gray's final call is the need for substantial and discursive changes in food system management.

Overall, this handbook on food crime is compelling, reinvigorating and inspiring reference that offers valuable knowledge, insights, and frameworks for understanding illegalities and immoralities in food chain. The conscientious discussions of different parts of food system, policy, and justice from a criminological point of view in the book, paints a picture of a criminological field that is rich and insightful. No research or literature review on criminological dimension of food would be complete without a reference to some of the chapters in this handbook. Thus, scholars in criminal justice, law, public policy, communication, criminology, psychology, and sociology disciplines would find this book an excellent reference. Additionally, it is an excellent resource for postgraduate students who want to delve and acquaint themselves with key research areas in crime and criminalities in any stage of the food chain. As an early career academic and researcher in food safety regulatory compliance, and aspiring food policymaker, this book was timely to my high degree studies. Consequently, the book is necessary and sets the stage for the evolvement of food criminology, a discipline that has the potential to become independent because $f$ potential harms food can generate. Lastly, the book can be used to inform the development of focused, effective, acceptable and appropriate food crime prevention policies and enforcement strategies.

\section{References}

Manning, L. (2017). Guest editorial. British Food Journal, 119 (1), 2-6. https://doi.org/10.1108/BFJ-09-2016-0446 